\title{
Visita domiciliar na Atenção Primária à Saúde: contribuições para a formação em Psicologia
}

\author{
House calls at Primary Health Care: \\ contributions to Psychology training
}

\section{Monica Lima' ${ }^{1}$ \\ João Batista Alves ${ }^{2}$ (C) \\ Louise Lago $^{3}$ (1) \\ Fernanda Rebouças 4 (1) \\ Leila Grave ${ }^{5}$}

\begin{abstract}
${ }^{1}$ Autora para correspondência. Universidade Federal da Bahia (Salvador). Bahia, Brasil. molije@gmail.com 2-3Universidade Federal da Bahia (Salvador). Bahia, Brasil. psicologojoaobatista.alves@gmail.com, louiselagopsi@gmail.com 4-5Secretaria Municipal de Saúde de Salvador (Salvador). Bahia, Brasil. nandareboucas27@gmail.com, leilagrave@gmail.com
\end{abstract}

RESUMO | INTRODUÇÃo: Há potencialidades e desafios no trabalho das psicólogas nos Núcleos de Apoio/Ampliado à Saúde da Família (NASF). Críticas giram em torno de um repertório profissional inadequado para este contexto, consequência da ênfase na formação clássica e ainda hegemônica. OBJETIVo: Refletir sobre o planejamento, execução e avaliação da estratégia de atendimento domiciliar em psicologia realizado pelo NASF, em Salvador-Bahia. MÉTODO: Trata-se de um relato de experiência. Utilizamos a supervisão compartilhada (SC), que consiste em: relato da situação concreta de atendimento domiciliar, registrado em Relato de Visitas; os sentimentos e afetações em relação ao que foi vivenciado; reflexões e sínteses sobre o atendimento domiciliar em relação às atuações clínicas clássicas. Nas SC quinzenais, os atendimentos domiciliares eram narrados pelos/as extensionistas/ os e preceptora e os registros de visita compartilhados reflexivamente. A análise foi realizada com base nas discussões ocorridas durante os momentos de SC, com ênfase no ato narrativo e bem como através dos relatos escritos das visitas. RESULTADOS: Realizamos 63 visitas domiciliares e destacamos duas dimensões: 1) mudanças no processo de trabalho, em relação à concepção hegemônica da atuação psicológica; 2) percepção de que o modo com que somos acolhidos/as nos domicílios reflete as possibilidades de cuidado, exigindo uma postura ativa, sensível, acolhedora na relação profissional-usuário/a. CONCLUSÃo: A atenção domiciliar apresentou-se como um desafio, requerendo a ampliação de habilidades, modos não tradicionais de se portar e comunicar, de maneira a facilitar o diálogo, a escuta, sendo uma estratégia para ampliar o repertório profissional.

PALAVRAS-CHAVE: Atenção Primária à Saúde. Formação do psicólogo. Atendimento domiciliar. Supervisão clínica. Clínica Ampliada.
ABSTRACT | INTRODUCTION: There are potentials and challenges in the work of psychologists in the Family Health Support Centers (NASF). Criticism revolves around an inadequate professional repertoire for this context, resulting from the emphasis on classical and still hegemonic training. OBJECTIVE: To reflect on the planning, execution, and evaluation of the house calls strategy in psychology carried out by NASF in Salvador-Bahia. METHOD: This is an experience report. We use shared supervision (SC), which consists of: reporting the concrete situation of house calls recorded in the Report of Visits; sharing feelings and affection in relation to what was experienced; reflections and syntheses on the house call concerning classic clinical practice. During the fortnightly $\mathrm{SC}$, house calls were narrated by the interns and the tutor, and the visit records were shared reflexively. The analysis was carried out based on the discussions that occurred during the moments of SC, with emphasis on the *narrative act* and also through the written reports. RESULTS: We carried out 63 house calls and highlighted two dimensions: 1) changes in the work process, in relation to the hegemonic conception of psychological performance; 2) perception that the way we are welcomed at home reflects the possibilities of care, requiring an active, sensitive, welcoming attitude in the professionaluser relationship. CONCLUSION: House calls presented themselves as a challenge, requiring the expansion of skills, non-traditional ways of behaving, and communicating in order to facilitate dialogue, listening, and as a strategy to expand the professional repertoire.

KEYWORDS: Primary Health Care. Psychologist education. House calls. Clinical supervision. Extended Clinic. 


\section{Introdução}

No âmbito do Sistema Único de Saúde (SUS), a Atenção Domiciliar é uma qualidade de atenção integrada às Redes de Atenção à Saúde (RAS), constituída por um rol de "ações de prevenção e tratamento de doenças, reabilitação, paliação e promoção à saúde, prestadas em domicílio, garantindo continuidade de cuidados" (Portaria n 825 , 2016). É direcionada a pessoas que apresentam estabilidade clínica, porém com demandas de atenção à saúde em contexto de restrição ao leito ou ao lar (temporária ou contínua) ou que vivenciem grau de vulnerabilidade em que esta oferta seja a mais adequada para o tratamento, paliação, reabilitação e prevenção de agravos, com vistas à ampliação de autonomia do/a usuário/a, família e cuidador/a. Dividida em três modalidades, compete à Atenção Primária à Saúde (APS) prestar Atenção Domiciliar do tipo AD1, através de acompanhamento regular em domicílio, em conformidade com as singularidades de cada caso e atuar no cuidado compartilhado com os outros níveis de atenção domiciliar AD2 e AD3 (Portaria no 825, 2016).

Maria Lacerda et al. (2006) $)^{1}$ propõem uma definição e diferenciação entre os termos atenção, atendimento, visita e internação domiciliares (este último, não sendo de competência da APS). Concordamos com os/as autores/as que a Atenção Domiciliar é a dimensão de maior amplitude, que engloba os outros termos. Entretanto, no que se refere ao atendimento domiciliar e à visita domiciliar, os utilizaremos como sinônimos ao longo desta comunicação, conforme o Caderno 39 (Ministério da Saúde, 2014a).

Nesse Caderno, o atendimento domiciliar compartiIhado e específico, ou apenas "visita domiciliar" (utilizaremos a sigla VD), está previsto como estratégia que configura mudanças no contexto de atuação, que precisam ser revisitadas à luz do cotidiano do trabalho e merecem uma reflexão teórica à altura das exigências postas às profissionais que as realizam e aos/às usuários/as que abrem suas casas para recebê-las/os. O mesmo documento afirma que a VD tem como finalidade "promover o acesso dos usuários restritos ao leito ou ao domicílio" e "pode ser realizado em conjunto com ao menos um profissional da equipe de $A B$ [atenção básica] (recomendado), servindo, também, como estratégia de educação permanente e manutenção de vínculo com essa equipe, ou apenas pelo profissional do NASF, após regulação e pactuação com a equipe vinculada" (Ministério da Saúde, 2014a, p.53).

Nessa direção, na caracterização dos tipos de atendimento desenvolvidos pelo NASF, podemos inferir a existência de dois referenciais: 1) o/a usuário/a, podendo o atendimento ser individual ou coletivo; 2) o/a profissional, sendo o atendimento específico conduzido por um/a único/o profissional e o compartilhado por profissionais de outras categorias ou mesmo outros serviços e níveis de atenção à saúde (Ministério da Saúde, 2014a).

No Caderno 39, o termo "específico" aparece associado tanto a atendimentos, quanto a atividades de grupo, contrapondo-se ao termo "compartilhado", quando a intervenção é produzida em conjunto por mais de um/a profissional, em que se estabelece um espaço de troca de saberes e manejo de vínculos. Ao mesmo tempo, os termos "individual" e "coletivo", ao serem associados aos tipos de ações do NASF, contrapõem-se em relação ao foco das intervenções; quando o atendimento, por exemplo, tem como direção um/a único/a usuário/a ou familiar (atendimento individual), ou quando se desenvolve para um conjunto de usuários/as do território (atendimento coletivo) (Ministério da Saúde, 2014a).

O conceito de "atendimento domiciliar compartilhado" é desenvolvido e utilizado de forma recorrente no texto do referido Caderno de Atenção Básica, havendo apenas uma menção ao termo "atendimento domiciliar específico" (Ministério da Saúde, 2014a, p. 53). Este último sugeriria a possibilidade de ocorrência de visitas por apenas um/a profissional NASF, sem a presença de outro/a integrante da SF/APS. Esta situação, no entanto, não nos parece interessante, em especial compreendendo o papel que um/a profissional da equipe NASF deve cumprir, na oferta de suporte técnico-pedagógico e clínico-assistencial a partir da lógica do apoio matricial, bem como a necessidade de ser apoiado/a por profissionais-chave no âmbito do cuidado orientado pelo território: os/as Agentes Comunitários/as de Saúde (ACS). 
Deste modo, em nossa experiência, toda e qualquer VD acontecia em parceria com um/a ACS, sendo esta, inclusive, uma orientação advinda da administração central da Secretaria Municipal de Saúde (SMS) de Salvador. Considerava-se imprescindível a presença deste/a profissional, inclusive, por questões de segurança e sua maior familiaridade com o que acontece na área de abrangência das Unidades de Saúde da Família (USF). Nesta direção, o conhecimento do território e o vínculo com a comunidade permitem melhor circulação, garantindo proteção em locais marcados pela presença do tráfico e pela constante exposição da população a situações de violência. Ao menos, é desta forma que essa situação é colocada nos discursos de muitos/as profissionais (inclusive as/os ACS), de modo que estas questões atravessam o cotidiano do trabalho.

Além disso, vale destacar que não contamos ainda com muitos estudos ou relatos de experiência sobre VD que foquem na atuação da psicóloga no contexto da Saúde da Família (SF), sendo necessárias mais reflexões que contribuam com o aprimoramento da sua prática. Kátia Rocha et al. (2017) apontam a precária contribuição da psicologia para pensar a utilização da VD como estratégia de prevenção de doenças e agravos e/ou promoção da saúde. Evidenciam como outras categorias profissionais e outros campos de estudo têm se debruçado mais sobre esta ferramenta de trabalho e defendem a construção de um "espaço no qual novas possibilidades de cuidado mais criativas, solidárias e inovadoras possam ser pensadas". A VD, neste caminho, abriria a oportunidade de repensar as práticas hegemônicas de cuidado em saúde, bem como o processo de formação para este campo de atuação.

Fabrício Leonardi (2018) discute como é diversa a forma com que a VD tem sido teorizada na literatura disponível, compreendendo-a, em geral, como um recurso, tecnologia, estratégia, modo de atendimento, instrumento, prática, método, dispositivo, atividade, processo de trabalho, em que é "possível entender as dinâmicas e as condições mais diversas em que estão inseridos os usuários e famílias, objetivando a realização de alguma ação específica ou conhecimento que subsidiem o planejamento da ação" (p. 9). Do ponto de vista desse autor, a VD possui sempre uma articulação mais ampla com processos sociais e históricos, relacionando-se sempre com as concepções das práticas de profissionais de saúde.

A visita domiciliar é uma ferramenta profissional que não apresenta funcionalidade em si mesma ou na relação sujeito/objeto. As demandas que são objeto de intervenções realizadas por meio de Visitas Domiciliares revelam, de alguma forma, a perspectiva mais geral e paradigmática de sua filiação, isto é, suas exigências e necessidades históricas, entrelaçando determinantes que se apresentam tanto no cotidiano, como nas relações mais amplas da sociedade e das classes sociais que articulam saberes e práticas (Leonardi, 2018, p. 7).

Podemos citar o estudo de Ana Pietroluongo e Tania Resende (2007), que, a partir de uma experiência no programa de visita domiciliar com a presença de psicólogas; implantado em um hospital do Distrito Federal, apontaram que a atuação psicológica neste contexto passava pela "capacitação familiar e consequente inclusão social do usuário de saúde mental", concluindo que:

por ser conhecedor da importância das relações para a construção de sentidos e pela sua disponibilidade para a escuta, definiu-se o papel do psicólogo dentro da equipe, na visita domiciliar, como precursor dessa mudança relacional (p. 23).

Devemos reconhecer também o esforço de referenciação teórica produzida no âmbito da Reforma Psiquiátrica Brasileira em torno do debate e do desenvolvimento de tecnologias psicossociais de atenção à crise em saúde mental, que tomam a atenção domiciliar como lócus privilegiado de trabalho e manejo das relações vinculares, como relatam Marcus Silva et al. (2009); Laura Côrtes et al. (2011). Como exemplo, temos a experiência do Programa de Atenção Domiciliar à Crise (PADAC), idealizado por Marcus Vinicius Silva, realizado em Salvador/Bahia, no contexto da formação de estudantes de psicologia para o trabalho no campo da saúde mental (Ministério da Saúde, 2014b). Nesse programa, partia-se da compreensão da atenção domiciliar como "um investimento mais intenso, envolvendo o domićlio como lócus de cuidados e como ponto de suporte para fortalecimento das relações familiares e das redes sociais" (Ministério da Saúde, 2014b, p. 137). 
Neste sentido, o deslocamento do setting terapêutico do espaço protegido dos consultórios e ambulatórios para o domicílio exige o desenvolvimento de um tipo de trabalho com ênfase nas dimensões relacionais (afetividade, criatividade, vínculos), compreendidas como tecnologias leves, em meio a situações sociais complexas. Emerson Merhy (1999) diferencia três tipos de tecnologia de cuidado que organizam o processo de trabalho em saúde: tecnologias "duras" (aparelhos e ferramentas de trabalho), "leve-duras" ("saber-fazer bem estruturado, bem organizado, bem protocolado e normatizado" de cada área profissional da saúde, p. 307) e as "leves". Merhy (1999) critica o excesso de investimento em torno das tecnologias leve-duras e duras, apostando no uso mais constante de tecnologias leves, traduzidas como

momentos de possíveis cumplicidades, nos quais pode haver a produção de uma responsabilização em torno do problema que vai ser enfrentado, ou mesmo de momentos de confiabilidade e esperança, nos quais se produzem relações de vínculo e aceitação

(Merhy, 1999, p. 308).

A tecnologia leve se remete então ao processo de relações inerentes a qualquer encontro entre usuário/a e profissional, pelo caráter relacional, que anuncia certa forma de agir entre os sujeitos implicados com a produção de saúde. Nesta direção, a tecnologia leve ganha relevo quando se "opera um jogo de expectativas e produções, criando-se intersubjetivamente alguns momentos interessantes como momentos de falas, escutas e interpretações" (Merhy, 1999, p. 308).

Cabe considerar também a crítica produzida extensamente na literatura sobre a inadequação da psicologia que, ao se inserir na atenção básica, dispõe de repertório profissional descompassado com os desafios deste contexto, reproduzindo a clínica clássica, de maneira restrita e individualizante, como destacam os estudos de Mônica Lima e Mônica Nunes (2006); Diogo Sousa et al. (2015); Aline Palmeira e Maria Guerra (2020). Com isso, fica evidente a urgência no desenvolvimento de propostas de atuação que contribuam para a formação ética e contextualizada de estudantes de psicologia mediada por aproximações sucessivas com a realidade social na qual estamos inseridos/as, através de processo de supervisão (Palmeira \& Guerra, 2020), garantindo, desta forma, o cuidado psicológico em sua dimensão subjetiva em condições objetivas de existência, como também defendem Mônica Lima (2005) e Marcus Silva (2007).

Desde o início da década de 2000, considerando os significados das atuações psicológicas construídas pelas psicólogas na rede pública de saúde/coletiva de Salvador, Lima (2005) identificou os desafios e perspectivas para a adequação dos fazeres psicológicos aos níveis primário e secundário de assistência. Desde então, em iniciativas exitosas, algumas induzidas pelo próprio Ministério da Saúde, como o Programa de Reorientação da Formação de Profissionais de Saúde (Pró-Saúde) e o Programa de Educação pelo Trabalho (PET-Saúde), há relatos de experiência de extensão, desenvolvida por Janaína Silva et al. (2016) e relatos de estágio curricular, fomentado por Mônica Lima et al. (2018). Nestas diversas ocasiões, havia o objetivo de aproximar crítica e positivamente as estudantes de psicologia da atuação profissional em equipes multiprofissionais e incentivar a perspectiva interdisciplinar, no contexto da atenção básica (incluindo NASF) e especializada, seguindo recomendações já institucionalizadas na Portaria $n^{\circ} 2.436$ (2017).

O principal inspirador para a fundamentação teórico-metodológica desta experiência que aqui destacamos, a VD, foi o conceito de Atuação Psicológica Coletiva (APC), compreendida como "o processo contextual de identificação de demandas, de planejamento e de execução de necessidades de atendimento psicológico socioeconômica e culturalmente orientado" (Lima 2005, p. 434). Buscamos colocar em prática dois elementos da APC: a) a escuta psicológica como uma conduta profissional socioculturalmente orientada; b) a reafirmação da importância da subjetividade no processo de saúde-doença-cuidado.

Estamos de acordo com Sergio Aragaki et al. (2012, p. 70) quando afirmam que a ampliação da inserção da psicologia para APS tem configurado "especial impacto para a abertura de um olhar psicológico à saúde" [tradução nossa]. Temos o intuito de problematizar com a oferta da própria prática psicológica no dia a dia do trabalho e da reflexão teórica, como aprimoramos o fazer psicológico considerando que, de modo geral, o atendimento domiciliar não fazia parte do repertório profissional da psicologia, supondo que esta nova configuração pode desfamiliarizar pressupostos e convenções arraigadas ao exercício profissional e ser um convite para superação de dificuldades e desafios urgentes. 
Nesta direção, esta comunicação tem como objetivo refletir sobre o planejamento, a execução e a avaliação da estratégia de atendimento domiciliar em psicologia realizado em Núcleos Ampliados de Saúde da Família (NASF) - antigos Núcleos de Apoio à Saúde da Família -, em Salvador Bahia. Trata-se de uma experiência de extensão universitária desenvolvida no âmbito da formação em psicologia para o contexto da atenção básica, dentro do projeto intitulado "Atuação Psicológica Coletiva no Núcleo de Apoio/ Ampliado a Saúde da Família: uma perspectiva da psicologia social construcionista, que contou com bolsas para iniciação à extensão universitária, via Pró-Reitoria de Extensão da Universidade Federal da Bahia (PROEXT/UFBA)".

\section{Método}

Este trabalho caracteriza-se como um estudo qualitativo. Trata-se do relato de experiência de um projeto de extensão universitária que contou com a participação de estudantes de psicologia extensionistas, de uma psicóloga-preceptora (profissional do NASF) e da professora-supervisora. Ele foi realizado entre os meses de abril de 2018 e julho de 2019 e consistia na realização de visita domiciliar (VD) a usuários e usuárias dos territórios adstritos de duas unidades de saúde da família (USF), localizadas em Salvador/Ba, que recebem apoio de uma equipe NASF. A análise desta experiência foi realizada através da supervisão compartilhada (SC).

A SC é uma proposta pedagógica não muito comum nos cursos de psicologia, necessariamente, por exigir a presença da professora-supervisora vinculada à instituição de ensino superior (IES) e da psicólogapreceptora vinculada ao serviço de saúde, juntas, para supervisionarem os/as estudantes. Esta particularidade tem várias potencialidades que não cabe aqui aprofundar, mas que pode ser sintetizada em quatro dimensões de significação: técnico-assistencial, político-formativa, afetivo-acolhedora e de educação permanente (Lima et al., 2018).

Em publicação posterior, no entanto, estas mesmas autoras desenvolvem a ideia de que a SC pode também ser compreendida como um método de pesquisa ou de produção do conhecimento (Lima et al., 2019). Ao se constituir como um espaço de elaboração das vivências, de alinhamento ético-político e de educação permanente, o momento da SC também permite a sistematização de uma série de experiências e a produção de novos sentidos a respeito de temas relacionados à formação em psicologia. Para estas autoras,

A principal ferramenta utilizada na supervisão compartilhada é o ato narrativo, como forma de produzir novos sentidos e posicionamentos nas relações sociais cotidianas e logo nas vidas das envolvidas. Esta centralidade na fala, quando as/ os estagiários narram o que fizeram, o que viram, onde foram, com quem estiveram (usuários, agentes comunitários de saúde, com a própria preceptora, em visitas domiciliares, grupos na unidade e fora dela), ou o que sentiram para a supervisora e preceptora, parte, então, da premissa, de que através do ato narrativo el ou autonarrativo compreendemos a ação, mais que isso, agimos (Lima et al., 2019, p. 142).

Para Gergen (2011, p. 233), "compreender uma ação é, em realidade, situá-la em um contexto de acontecimentos precedentes e consequentes". Além disso, em sua opinião, a "autonarração se refere à explicação que um indivíduo apresenta sobre a relação entre acontecimentos autorrelevantes através do tempo" (p. 233). [traduções nossas] Os momentos da SC, portanto, se constituíam como espaços nos quais as/ os extensionistas narravam os acontecimentos e, junto à preceptora e professora-supervisora, discutiam sobre os efeitos destas experiências para a formação, produzindo processos de desfamiliarização.

Spink e Frezza (2013, p. 10) utilizam o termo "desfamiliarizar" - "ressignificação contínua e inacabada de teorias" - em detrimento de "desconstrução", inspiradas nas ideias de Tomás Ibánez, partindo da noção de que "criamos espaço, sim, para novas construções, mas as anteriores ficam impregnadas nos artefatos da cultura, constituindo o acervo de repertórios interpretativos disponíveis para dar sentido ao mundo". Então, para dar novos sentidos ao atendimento em domicílio, tínhamos como ponto de partida o repertório profissional da clínica clássica, tomada como um saber-fazer bem estruturado, que justamente esteve sob foco da desfamiliarização através do ato narrativo, indo ao encontro das inúmeras novas possibilidades do fazer psicológico. Dito de modo mais direto, desfamiliarizar é adotar "um processo reflexivo acerca de posturas e ideias que se propõem imutáveis impedindo a construção e elaboração de outras" (Spink \& Frezza, 2013, p. 10). 
No que diz respeito à dinâmica, as supervisões compartilhadas aconteciam quinzenalmente, em uma das duas USFs cobertas pela equipe NASF, sempre com a participação da professora-supervisora, preceptora e os/as extensionistas, com duração de três horas e meia. Nesses encontros, os/as extensionistas iniciavam narrando as atividades que foram desenvolvidas. Em geral, em todos os encontros, os/as extensionistas/os e também a preceptora narravam visitas domiciliares e/ou suas repercussões para o acompanhamento das famílias. Além disso, como tínhamos o objetivo de produzir conhecimento sobre essa modalidade de tecnologia leve, especificamente para atuação em psicologia, refletimos também sobre as particularidades de estar no domicílio e realizar intervenções com a finalidade de cuidar dos aspectos subjetivos do processo saúde-doença-cuidado em situações concretas de existência.

Além da produção oral nos encontros, os/as extensionistas bolsistas traziam descrições sobre os casos em si, como também aspectos relacionados ao planejamento (pactuações, definições de atores/atrizes, objetivo/s) e reflexões sobre a própria visita domiciliar, a exemplo de como chegaram à casa, como foram recebidos/as, quantas pessoas tinham, como ocorreu o atendimento, como se organizaram quando tinha muitos/as membros/as e queriam falar com alguém em particular, quando havia crianças ou pessoas idosas, entre outros aspectos.

Portanto, os procedimentos desenvolvidos no momento da SC eram: (a) relato da situação concreta de atendimento domiciliar, antes registrado em diários de atendimentos dos/as extensionistas, os quais chamaremos de Relato de Visitas; (b) os sentimentos e afetações em relação ao que foi vivenciado; (c) reflexões e sínteses sobre o atendimento domiciliar em relação às atuações clínicas clássicas.

Ao se constituir como um relato de experiência, salienta-se que esta comunicação não foi submetida à avaliação de um comitê de ética em pesquisa. Obedece, todavia, aos inúmeros procedimentos éticos, como sigilo das pessoas envolvidas, cuidado no compartiIhamento de informações e atenção para não produzir riscos e prejuízos com os relatos apresentados e reconhecendo, desta forma, junto a outras autoras (Palmeira \& Guerra, 2020) a importância deste tipo de reflexão, gerada a partir de uma experiência de extensão que possui potencial para contribuir com a formação e a atuação prática da psicologia no contexto da saúde. Em alguns momentos destacamos trechos dos Relatos de Visitas produzidos pelos/as extensionistas, para oferecer evidências narrativas, e adotamos nomes fictícios. Neste particular, cabe ressaltar que ficamos atentos/as à Resolução CNS 510, no Art 1, especialmente, o inciso VII, que diz respeito ao presente tipo de estudo realizado.

As ideias que apresentamos aqui são fruto das discussões realizadas nas supervisões compartilhadas, sempre levando em conta a importância da narração nos termos apontados pela psicologia social de base construcionista. Destacamos que, nestes diálogos, novos significados vão sendo construídos no cotidiano das visitas e na própria supervisão, possibilitando que possamos nos pautar no processo de desfamiliarização da produção de práticas discursivas, como nos orienta Spink e outros/as autores/as que nos servem de inspiração, conforme apresentado nas linhas precedentes.

Partindo da noção de desfamiliarização, destacamos que esta experiência não se reproduz sem o processo de trabalho que conjuga o princípio de territorialização entre a SF e a comunidade. As conclusões explicitadas não são extensivas a qualquer tipo de atenção domiciliar que não atenda ao menos esta premissa. Tampouco as análises elaboradas coletivamente na supervisão compartilhada, e explicitadas na seção de discussão, se generalizam como resultados independentes do contexto e perspectivas teóricas daqueles/as que realizaram as visitas domiciliares e refletem sobre sua própria prática. Há quem perceba limitações nos argumentos apresentados justamente por esta última característica, valendo-se do princípio de neutralidade científica, que não é o caso da abordagem construcionista adotada neste estudo. No entanto, uma das autoras tinha função diferenciada por não executar a visita domiciliar, podendo servir como um distanciamento regulamentar para não sucumbir ao envolvimento pouco crítico ou demasiadamente crítico, da análise sobre as visitas domiciliares em psicologia. 


\section{Resultados e Discussão}

Durante esta experiência, foram realizadas 63 visitas domiciliares (VD), 28 reuniões de supervisão compartilhada, 23 participações em reuniões de equipe NASF e 21 em reuniões com Equipes de Referência da Saúde da Família (eSF). As VD aconteciam após discussão do caso e pactuação das ações de cuidado em reuniões de matriciamento com as eSF ou pactuação nas reuniões específicas da equipe NASF. Elas eram realizadas pelos/as extensionistas sempre acompanhados/as, no mínimo, do/a Agente Comunitário/a de Saúde (ACS), e em alguns momentos com a presença de outros/as profissionais, como psicóloga (preceptora), terapeuta ocupacional, fisioterapeuta, assistente social, nutricionista, médica, enfermeira. Em algumas VD, assim como nas demais atividades conjuntas, também houve a presença de outros/as estudantes de diferentes categorias profissionais da saúde, atuantes na Estratégia Saúde da Família. Isso possibilitou a troca de experiência com pares, em processo de formação, e não apenas com os/as trabalhadores/as das unidades.

De maneira geral, os casos acompanhados através de VD envolviam alguma necessidade relacionada à saúde mental, percebida pela equipe como demanda de atenção do núcleo de saber da Psicologia. As VD eram um dispositivo significativo para o gerenciamento das necessidades de cuidado dos/as usuários/ as assistidos/as, com a oferta de escuta, mediação das relações familiares e comunitárias, garantindo uma presença intensa e orientada, para utilizar um termo de Silva (2007), no desenvolvimento de uma clínica psicossocial em saúde mental. Era possível para a equipe, através do trabalho das/os extensionistas, garantir a intensificação dos cuidados, além da manutenção e fortalecimento dos vínculos dos/as usuários/as com a unidade.

A partir desta experiência, gostaríamos de desenvolver dois aspectos da VD que nos pareceram fundamentais de serem considerados no processo de formação de profissionais da psicologia para o uso desta tecnologia de trabalho. A primeira dimensão diz respeito a mudanças no processo de trabalho, pensando que o modelo clássico de atuação (psicoterapia) ainda cumpre um papel significativo na construção do fazer da psicóloga, atravessando todo processo de formação. A segunda dimensão refere-se ao acoIhimento, que, no contexto da VD, precisa ser fortemente pensado como uma "via de mão-dupla", no espaço da relação profissional-usuário/a, uma vez que o modo com que somos acolhidos/as nos domicílios reflete as possibilidades de cuidado, exigindo uma postura ativa, mais sensível, acolhedora no espaço da relação profissional-usuário/a.

\section{Da atuação psicológica clássica ao inventivo}

Com o deslocamento do contexto terapêutico clássico para o domicílio, outros lugares simbólicos são ocupados; o/a profissional de saúde sai da posição passiva, daquele/a que espera, para ser aquele/a que vai até o/a assistido/a. Este movimento é condizente com as premissas da ESF, clínica ampliada, acoIhimento, oferta organizada e não exclusivamente na demanda espontânea, como qualificam Vladimir Arce e Carmen Teixeira (2017), entre outras. A oferta organizada se constitui como uma das características principais, junto com o acolhimento, que diferencia os modelos assistenciais hegemônicos de saúde, ainda vigentes, para uma perspectiva alternativa e que implemente, de fato, os princípios do SUS.

Nesta direção, o desafio é posto a todo/a profissional de saúde. No entanto, após um ano de práticas e reflexões sistemáticas sobre as atuações psicológicas em parceria com demais profissionais, em contexto de atuação tão singular, podemos afirmar que atuar em Saúde da Família implica em modificações significativas na concepção tradicional do processo de trabalho da psicóloga.

Primeiro, porque, de modo geral, ainda é presente entre profissionais de psicologia a premissa de que a pessoa deve buscar o tratamento psicológico por iniciativa própria, apostando que haverá mais possibilidade dela criar uma "demanda psicológica", implicando-se no tratamento: "a demanda espontânea, ou sem intermediário, é vista como a que pode mais facilmente indicar um trabalho psicoterapêutico mais proveitoso, no sentido de não favorecer o surgimento, a priori, de pedidos insustentáveis como os trazidos por determinados encaminhamentos" como destacado por Lima (2005, p. 187), quando entrevistou psicólogas vinculadas ao SUS. 
No âmbito da SF, o contato cotidiano com os/as usuários/as permite que demandas de saúde diversas possam ser identificadas não apenas pelas pessoas que buscam diretamente os serviços da APS, mas por familiares, por profissionais de diferentes categorias ou mesmo pela própria comunidade. Nesta rotina, a atuação da psicóloga dá-se como uma das tantas colaborações possíveis no processo do cuidado longitudinal das pessoas/famílias adscritas às USF, processo este que envolve diferentes dimensões de vida, agentes terapêuticos e lócus de intervenção.

Ainda que o núcleo de saber da Psicologia seja fundamental para o acompanhamento de diversos casos na SF, inclusive quando da necessidade da assistência direta, as ideias de "demanda psicológica" e de "tratamento psicológico" esvaziam-se de sentido neste contexto, uma vez que existem outros/as agentes de promoção de saúde cujas ações (compartilhadas ou não) impactam direta ou indiretamente na "dimensão psicológica" dos/as usuários/as, não sendo a psicóloga a única interventora deste campo. Neste, o caminho do cuidado prescinde que a busca seja feita necessariamente pela pessoa endereçando um pedido terapêutico ao/à profissional.

Estes elementos pressupõem uma outra lógica de ofertar o cuidado completamente oposta ao procedimento da psicologia clínica clássica, conforme relato de visita domiciliar abaixo²:

Chegamos na casa dele [Alan/usuário] e da família. Fomos recebidos por Laura [sobrinha] e Irani [Avó]. Carolina [irmã] estava na cozinha e veio logo em seguida. Alan [usuário] desceu e recusou-se conversar conosco. Núbia [Terapeuta Ocupacional NASF] explicou

à família o motivo de nossa visita. Irani gritou de baixo, avisando que Núbia subiria para falar com ele. Eu [extensionista] fui junto. Ficamos perto da escada. Núbia me apresentou. Eu disse "olá, Alan" e ele foi lá dentro pegou uma camisa e saiu da casa. Descemos e conversamos mais. Carolina disse que está exausta e não fala mais com ele, para não "dá um murro" nele.

Bruna [tia] apareceu e Núbia falou sobre a conversa que tivemos com o CAPS AD. A ideia é eu me aproximar de Alan, criar algum vínculo com ele e ajudar a mediar

a ida dele ao CAPS AD [...] Núbia acredita que preciso trabalhar com ele a questão do Projeto de Vida. (Relato de Visita realizada no dia 16 de abril de 2018).
Neste caso, em particular, tratava-se de uma pessoa que fazia uso de substâncias psicoativas e que já era acompanhada pela equipe de Saúde da Família e pela equipe NASF há alguns anos. A presença do extensionista foi pensada em reunião de matriciamento com CAPS AD como uma nova aposta de vínculo para o caso. Neste contexto, foram realizados alguns investimentos. Este é apenas um exemplo de como a necessidade de organizar a oferta de cuidados em saúde mental, no âmbito da atenção básica, exige uma postura ativa de aproximação com os sujeitos e familiares, não cabendo, em todo momento, a espera de que surja uma demanda eminentemente psicológica através de um pedido declaradamente ativo.

Tomando ainda como referência o trecho do relato de visita citado acima, é possível identificar que uma segunda modificação a destacar no processo de trabalho da psicologia, neste contexto de atuação, ocorre com o deslocamento do cuidado do sujeito para o grupo familiar, independentemente da vertente teórica que a psicóloga utilize. O convite é gerenciar o cuidado do/a usuário/a que pode ser o "sujeito-motivo da oferta da VD", refletindo sobre as repercussões do processo saúde-doença-cuidado em todo grupo familiar.

[...] a família ocupa uma posição preponderante, decisiva e inegável tanto no estado de saúde dos sujeitos, como nas possibilidades de sucesso do tratamento. Contribuir para o fortalecimento dos seus vínculos familiares e estar todo o tempo atento para o estado dessa família traz benefícios não só para o sujeito, como para as pessoas que estão à sua volta e evidencia a importância de que o acompanhamento se estenda para todos aqueles que estão no domicílio

(Silva et al., 2009, pp. 4-5).

A terceira modificação se dá, principalmente, porque as psicólogas saem de um ambiente protegido de trabalho (consultório e/ou ambulatório, antes disso, da proteção dos Serviços Escola) para o domicílio dos/as usuários/as. Este elemento é ainda mais desafiador, pois, ao destacarmos-lhe, não tratamos apenas de estar fora das paredes físicas do consultório, mas de pensar em atuações que envolvam o território, como destacam Mônica Lima et al. (2011).

2 Todos os nomes presentes nos Relatos de Visitas são fictícios. 
Em nossa experiência, foi possível acompanhar o desconforto vivido pelos/as extensionistas do projeto no encontro com o dispositivo VD. De forma geral, os modelos clássicos de oferta psicológica (psicoterapia) oferecem um arcabouço imaginário e de conduta sobre o processo de trabalho, atravessando a produção de sentidos a respeito do encontro terapêutico no setting domiciliar. Isso quer dizer que os/as extensionistas ou estagiários/as em formação do curso de psicologia necessitam lidar com o esforço de produzir uma série de distanciamentos e aproximações desse modelo clássico, a fim de se apropriar de novas tecnologias relacionais, produzindo ações de cuidado em domicílio. Podemos usar como exemplo um outro trecho do relato de visitas, escrito por um dos extensionistas, a partir das vivências do dia 17 de setembro de 2018:

Quando chegamos à casa, Joelma [usuária] e o esposo nos receberam. Eles decidiram quem conversaria comigo primeiro e fomos ao primeiro quarto da casa, chamado "quarto dos brinquedos", onde ficavam espalhados os brinquedos das duas filhas do casal. Joelma pegou duas cadeiras, dispôs uma em frente à outra e fechamos a porta para conversar. Osana (ACS) ficou na sala, ajudando a olhar as crianças. Eu me senti muito desconfortável com aquele processo. Me veio à cabeça as diversas críticas que ouvi sobre o fato de a psicologia chegar nos espaços de trabalho reproduzindo o formato da "clínica" (clássica), no modelo de consultório privado.

Estávamos ali, na casa de uma usuária e fazíamos do seu quarto um atendimento entre quatro paredes.

o pior é que na realidade não fui eu que construí aquele setting ou, na qualidade de profissional em formação, ofereci o enquadre da relação. Eu me senti enquadrado, na forma como se veicula no imaginário social que deve ocorrer um atendimento de psicologia. Cheguei, e me foi oferecida uma cadeira disposta de frente à outra, de portas fechadas. Aquele desconforto só foi sendo digerido quando, na conversa com a preceptora e a professorasupervisora, pude perceber o quão inusitado aquele contexto parecia. Estava na casa de uma usuária, oferecendo-Ihe continuidade de uma escuta, às portas fechadas, mas com as janelas abertas, e as crianças circulando pela sala. Um espaço de cuidado, inserido no cotidiano da vida comum. Produção de

sentidos inclusive sobre a forma de se apropriar naquele espaço. [..] Foi naquele quarto com Joelma que conversamos sobre a relação dela com o marido, com as filhas, com a sua função de mãe-cuidadoracozinheira-protetora. Onde descrevemos no papel a quantidade de horas de trabalho dedicado à casa e à família e pensamos sobre como aquilo tudo afetava a sua saúde e a sua autoimagem, como interferia nas suas relações e nos seus projetos para o futuro.

A casa e o bairro formam o território conhecido, vivido. Às vezes, pode ser preciso distância, a fim de que possamos pensar sobre esse território e as coisas que nele acontecem. Por outro lado, em outros momentos, é necessário estar nesses espaços para compreendermos o movimento pulsante e paradoxal das relações, descobrirmos novas formas de nos colocar no terreno existencial pelo qual caminhamos. Nesta direção, a atenção domiciliar apresentou-se como um desafio, requerendo ampliação de habilidades, outros modos de se portar, comunicar, de maneira a facilitar o diálogo, a escuta, adequando-se ao contexto em que a ação acontece. Segundo Edirlei Santos e Débora Kirschbaum (2008),

O processo de adentrar o domicílio dos usuários requer preparo, habilidades de comunicação, ética profissional, conhecimento dos mecanismos para prover à família uma assistência de cunho educativo, pautados em ações de prevenção e principalmente de promoção à saúde da população, assim como, maiores esclarecimentos acerca das relações entre espaço público e privado concebidos por usuários e profissionais de saúde de modo não necessariamente coincidente, trazendo conseqüências importantes para a implementação das práticas de saúde coletiva no país

(p. 226).

Na direção de refletirmos sobre o adentrar o domicílio, o acolhimento como uma ferramenta nos parece fundamental na construção de uma atuação psicológica inventiva.

\section{Acolhimento no domicílio}

No trabalho com a VD, interferimos no cotidiano de uma família/casa/comunidade. Neste contexto, podemos nos deparar com diversas situações, algumas delas, às vezes, inusitadas, como não encontrar os/ as residentes em casa, sermos abordados/as por vizinhos/as nos informando o itinerário destas pessoas em questão, encontrá-las dormindo ou dedicadas às suas tarefas diárias, nem sempre disponíveis para nos receber, mesmo que o atendimento tenha sido devidamente agendado com a família de maneira prévia, através da ação do/a ACS. Com isso, é imprescindível assumirmos uma postura de flexibilidade e criatividade na nossa forma de condução do trabalho, abertos/ as às diversas configurações que se apresentam. 
Cheguei na Unidade quase 9 horas. Encontrei com

Sueli [ACS] na Praça do Fim de linha, me sentindo bastante cansado. Sueli disse para darmos um tempo, pois as pessoas deveriam estar dormindo na casa que visitaríamos. No dia anterior eu liguei para casa de Alan e consegui falar com ele, avisando que iria visitá-lo e ele concordou. Quando, enfim, nos dirigimos à casa dele, encontramos Irani e Carolina, que nos disseram que Alan ainda dormia, pois passara a noite inteira acordado fumando e tomando café. Sueli conduziu o processo, decidimos ir embora e tentar voltar mais tarde ou marcar outro dia. (Relato de Visita realizada em 26 de abril de 2018).

Ao mesmo tempo, durante as visitas, também é comum as pessoas sentirem a necessidade de oferecer algo para beber ou comer, um lugar confortável para sentar, um ventilador para nos refrescar, como quem recebe uma visita de um/a amigo/a ou parente. Esse tipo de acolhimento, de modo geral, pode evidenciar o grau de abertura daquela pessoa para com a nossa presença, uma possível expectativa de que tenhamos uma passagem mais agradável em sua residência ou, por vezes, certa honradez em receber profissionais da unidade de saúde em seu lar. O acolhimento, nesse sentido, é uma "via de mão dupla". O grau com que nos acolhem em sua casa abre maior ou menor espaço para que possamos acolher suas angústias e dificuldades.

Luana [usuária] estava preocupada sobre nos servir algo, achava que era necessário, mas sentia-se muito nervosa com a situação, pois tinha receio se iria "fazer bonito, fazer direito". A psicóloga [preceptora] reiterou diversas vezes que não era necessário, que era comum fazermos visitas, que era [parte] [d]o trabalho. Ainda assim, quando ela nos ofereceu água, a profissional aceitou, e perguntou como ela se sentia mais à vontade. Luana diz que se sente mais confortável se ela [psicóloga] fosse à cozinha e se servisse, do que trazer a jarra para a sala. Em seguida, nos oferece nozes e damascos que já estavam arrumados numa mesa na sala ao lado. Aceitamos e agradecemos, ela parece ter ficado contente [...]. Mesmo após um longo tempo decorrido da visita, fala que ainda está se sentindo ansiosa, que tem sentimentos contraditórios, de que é bom nos receber, mas se sentiria aliviada se fossemos embora. Quando de fato nos despedimos, insiste para que fiquemos mais, fala sobre a chuva, de modo que nos estendemos mais alguns minutos antes de sair. Ao final agradece, e ainda desculpa-se por não ter feito um lanche (mesmo tendo servido as nozes) ou "por qualquer coisa". (Relato de Visita realizada em 16 de abril em 2019).
A conduta dos/as profissionais varia nesse tipo de situação. Às vezes, pode ser interessante aproveitar aquele momento de abertura e usufruir da oferta de água, por exemplo, permitindo que o diálogo aconteça de maneira fluida, com o gesto materializando a dimensão da troca que deve fundamentar a relação. Em outros contextos, pode ser estratégico negar a oferta demasiada de outras coisas, a fim de demarcar o espaço daquela relação, comprometido com um lugar profissional e terapêutico, com foco nos sujeitos, em seus processos de sofrimento, decorrente das experiências de ruptura oriundas da relação saúde-doença-cuidado. Há profissionais, por sua vez, que assumem esta última postura de forma cristalizada, garantindo o distanciamento que assumem como base de seu trabalho. Em contexto de atenção às famílias que se encontram em extrema vulnerabilidade social, essas questões de ter ou não o que oferecer, e da aceitação ou não por parte dos/as profissionais, pode ser um entrave para o estabelecimento de vínculo, pois pode se configurar como marcador da distância social, étnico-racial e cultural, evidenciando as diferenças de pertencimento.

Destacamos uma experiência vivenciada por um extensionista, que supomos ter conseguido vencer os distanciamentos citados, dando uma nova direção para o cuidado da usuária, que, vivendo em situação de extrema vulnerabilidade social, não dispunha de móveis (sofá ou cadeira) para receber a equipe que a visitava:

Eu sentei no chão ao lado dela. Ela gostou bastante aparentemente. Pela primeira vez senti que talvez eu tenha espaço para conversar com Rosa [usuária]. Ela começou a se abrir e falar o quanto as coisas são difíceis para ela. (Relato de Visita, realizado em 17 de

julho de 2018).

Por outro lado, é possível ocorrer situações inversas, quando a pessoa demonstra total desconforto com a nossa presença. Podem nem sequer abrir a porta, nos recebendo por trás das grades, ou ignorando nosso chamado, garantindo, desta forma, a defesa de sua intimidade no exercício de sua cidadania. Muitas vezes, interpretam-se tais situações como "resistências" das pessoas ao tratamento ou falta de preocupação com a própria saúde, afinal, negam o "privilégio" de ter um atendimento especializado dentro de sua própria casa, ou até como recusa da intervenção dos/as profissionais do SUS por terem planos privados de saúde. Não estamos de acordo com uma compreensão reducionista que enquadre a multiplicidade de 
situações em concepções que, a priori, desconsideram sua subjetividade e nos afinamos com a síntese oferecida a seguir:

As questões e dificuldades decorrentes da prática de atenção domiciliar mobilizam também o assunto do domicílio como lócus de cuidado, local este que

se estabelece numa dualidade entre ser privado e público ao mesmo tempo. Embora as próprias famílias reconheçam hoje o valor e as vantagens desse modelo, elas reivindicam certa garantia à intimidade; códigos e sinais emergem, nem sempre de modo nítido, podendo

se caracterizar como sinais de resistência da família à intervenção de profissionais, por estarem invadindo sua intimidade (Côrtes et al., p. 85).

Desta maneira, não ignoramos os efeitos nem sempre convenientes de nossa presença. Podemos recorrer à noção de humilhação social, descrita por Gonçalves-Filho (1998), como um tipo de angústia disparada pela enigmática experiência ancestral de submissão às desigualdades sociais, que se atualiza constantemente nas situações estabelecidas em relações de poder, as quais não queremos perder de vista e que deve ser considerada sempre que pensarmos a nossa atuação no âmbito da Atenção Básica, em especial, nos territórios marcados pela pobreza e extrema vulnerabilidade social, fruto da exploração à qual nossa gente é historicamente submetida.

Neste sentido, são oportunos os questionamentos produzidos por Rocha et al. (2017), que servem como balizadores na reflexão sobre a função ética e política que a VD pode assumir, com as quais dialogamos profundamente em nosso processo de aprendizagem sobre esta tecnologia.

Do ponto de vista ético, a história da utilização da visita domiciliar como ferramenta privilegiada da assistência social e da saúde (referência) [assim no original], nos impõe um questionamento ético sobre os sujeitos el ou grupos aos quais direcionamos prioritariamente as nossas práticas. De quais critérios nos valemos para eleger determinados indivíduos ou famílias como principais beneficiados desta estratégia? E, ao fazermos esta eleição, que subjetividades e que formas de relação estamos legitimando ou reforçando? Portanto,

a adoção da visita domiciliar por profissionais de quaisquer áreas de atuação deve ser acompanhada por um questionamento constante, especialmente com

a intenção de não reafirmar relações de poder nas práticas de atenção à saúde de determinados grupos sociais. (p. 171-172).

\section{Considerações}

Entrar na casa de uma pessoa é adentrar em uma dimensão bastante íntima de sua vida psicossocial. Naquele espaço, encontram-se expressos aspectos importantes para estruturação dos sujeitos, com cargas afetivas variadas. A relação com a casa, com a forma como ela é ocupada e organizada, com os cômodos, com os objetos e pertences que a compõem são todos elementos que garantem um determinado modo de subjetivação, ou seja, uma determinada maneira de os sujeitos se colocarem no mundo, definindo a si mesmos e sua relação com o mundo. Por isso, a visita domiciliar pode ser uma ação extremamente invasiva, dependendo da maneira como é estabelecida. Nesta direção, apostar no uso de tecnologias leves é o ponto de partida para ação vincular: cumplicidades, confiança e esperança mútuas, entre quem oferece e quem recebe, não um mero ato prescrito.

Portanto, é imprescindível que a visita domiciliar seja precedida do estabelecimento de propósitos e definição sobre quem e como abordar as pessoas residentes do domicílio, de acordo com cada contexto territorial, comunitário, residencial, familiar e subjetivo. Para tanto, é adequado avaliar se esta é a melhor estratégia de aproximação, escuta, troca e intervenção para aquele momento do processo de cuidado. A não atenção a estes aspectos pode nos fazer incorrer no risco de uma ação contraproducente, ou mesmo, iatrogênica.

Neste sentido, mais significativo do que entrar na casa de um sujeito para garantir o acesso a mais informações sobre a vida dele e de sua família - como, de fato, tende a ser um dos objetivos de uma visita domiciliar - ou apenas garantir o acesso para quem não consegue ir ao serviço, destacamos a potência da forma como se entra, que pode abrir possibilidades para construção de pactos de cumplicidade e respeito. Parece-nos, assim, que a figura da ACS é fundamental para que se diminuam os possíveis efeitos nocivos, potencializando a construção de vínculos. Os/as ACS operam como verdadeiros/as mediadores/as dos vínculos, das famílias para com a equipe, e o agenciamento que produzem na oferta de atenção domiciliar é extremamente necessário para aumentar os efeitos terapêuticos das intervenções de toda a equipe. 
Para a formação em psicologia, o trabalho com a VD no contexto da Atenção Primária pode se colocar como uma maneira potente de produção de sentidos sobre a relação terapêutica, bem como auxiliar na apreensão e aquisição de novas tecnologias de cuidado. As sutilezas presentes neste âmbito de trabalho requerem uma afinação do olhar e da escuta que transcenda a formatação típica das grandes teorias psicológicas, abrindo espaço para uma atuação realmente interdisciplinar, em que a troca de saberes e a orientação ética para o cuidado se coloquem como centro das práticas das equipes a partir de diretrizes clínico-sanitárias compartilhadas entre os/as profissionais.

Resgatamos, desta maneira, o conceito de Atuação Psicológica Coletiva (Lima, 2005; Lima \& Nunes, 2006 para afirmar a necessidade de que, no âmbito do trabalho do NASF, a psicologia também se coloque com a possibilidade de garantir o reconhecimento da produção de subjetividade na relação entre saúde-doença-cuidado, através do desenvolvimento de uma escuta socioculturamente orientada. A psicologia na Saúde da Família tem uma função primordial de refletir criticamente sobre o próprio papel na comunidade, principalmente ao adentrar espaços privados para as famílias. É só a partir desta leitura que podemos operar uma prática ainda mais potente, não como forma de reafirmar mais um espaço de atuação da categoria, mas para o estabelecimento de um desvio das práticas normatizantes e autoritárias, historicamente propagadas na saúde.

\section{Contribuições das autoras}

Monica Lima escreveu e coordenou o projeto de extensão, participando das supervisões compartilhada, análise das informações produzidas, escrita do texto e revisão crítica geral. João Batista Alves e Louise Lago foram bolsistas do projeto, participando das supervisões compartilhadas, fazendo relatos das visitas domiciliares, análise das informações produzidas, escrita de todas as etapas do texto. Fernanda Rebouças foi preceptora, participando das supervisões compartilhadas, análise das informações produzidas, escrita do texto. Leila Grave participou da análise das informações produzidas, fez contribuições sobre o tema do ponto de vista teórico-prático.

\section{Conflitos de interesses}

Nenhum conflito financeiro, legal ou político envolvendo terceiros (governo, empresas e fundações privadas, etc.) foi declarado para nenhum aspecto do trabalho submetido (incluindo, mas não se limitando a subvenções e financiamentos, participação em conselho consultivo, desenho de estudo, preparação de manuscrito, análise estatística, etc.).

\section{Referências}

Aragaki, S. S., Spink, M. J., \& Bernardes, J. S. (2012). La Psicología de la Salud en Brasil: transformaciones de las prácticas psicológicas en el contexto de las políticas públicas en el área de la salud [Psicologia da Saúde no Brasil: transformações das práticas psicológicas no contexto das políticas públicas na área da saúde]. Pensamiento Psicológico, 10(2), 65-82. http://www. scielo.org.co/scielo.php?script=sci arttext\&pid=S1657$89612012000200007 \&$ Ing=en\&tlng=es

Arce, V. A. R., \& Teixeira, C. F. (2017). Práticas de saúde e modelo de atenção no âmbito do Núcleo de Apoio à Saúde da Família em Salvador (BA). Saúde em Debate, 41(spe), 228240. https://doi.org/10.1590/0103-11042017s317

Côrtes, L. A. S., Silva, M. V. O., \& Jesus, M. L. (2011). A atenção domiciliar em saúde mental realizada por estagiários de Psicologia no Programa de Intensificação de Cuidados. Psicologia: teoria e prática, 13(2), 76-88. http://pepsic. bvsalud.org/scielo.php?script=sci arttext\&pid=S151636872011000200006\&lng=pt\&tlng=pt

Gergen, K. (2011). Realidades y relaciones: Aproximaciones a la construcción social [Realidades e relações: Abordagens à construção social]. (2 ${ }^{\mathrm{a}}$ ed.). Paidós.

Gonçalves-Filho, J. M. (1998). Humilhação social - um problema político em psicologia. Psicologia USP, 9(2), 11-67. https:// doi.org/10.1590/S0103-65641998000200002

Lacerda, M. R., Giacomozzi, C. M., Oliniski, S. R., \& Truppel, T. C. (2006). Atenção à saúde no domicílio: modalidades que fundamentam sua prática. Saúde e Sociedade, 15(2), 88-95. https://doi.org/10.1590/S0104-12902006000200009

Leonardi, F. (2018). Visitas domiciliares: Desafio à atenção básica e saúde mental. Cadernos Brasileiros de Saúde Mental/ Brazilian Journal of Mental Health, 10(26), 01-18. http://stat. intraducoes.incubadora.ufsc.br/index.php/cbsm/article/ view/2077 
Lima, M. (2005). Atuação psicológica coletiva: uma trajetória profissional em unidade básica de saúde. Psicologia em Estudo, 10(3), 431-440. https://dx.doi.org/10.1590/S1413$\underline{73722005000300011}$

Lima, M., \& Nunes, M. O. (2006). Práticas psicológicas e dimensões de significação dos problemas de saúde mental. Psicologia: Ciência e Profissão, 26(2), 294-311. https://dx.doi. org/10.1590/S1414-98932006000200011

Lima, M., Alves, J. B., Rebouças, F., \& Grave, L. (2019). “Caruru de Balbúrdia": supervisão compartilhada em psicologia como prática de pesquisa. In B. Mesdrado, \& M. M. Teti (Orgs). Problemas, controvérsias e desafios atuais em psicologia social (Vol. 3, pp. 132-151). Abrapso. https://www.abrapso. org.br/download/download?!D DOWNLOAD $=610$

Lima, M., Nunes, M., Alves, V., \& Santos, M. (2011). Reflexões teórico-metodológicas para a interpretação das intervenções e do cuidado no território em saúde mental. Revista Eletrônica de Comunicação, Informação e Inovação em Saúde, 5(4). https://www.reciis.icict.fiocruz.br/index. php/reciis/article/view/772

Lima, M., Rebouças, F., \& Grave, L. (2018, 25 a 27 de janeiro). Formação em psicologia: Dimensões da supervisão compartilhada na atenção básica à saúde. Actas do $12^{\circ}$ Congresso Nacional de Psicologia da Saúde, Promover e Inovar em Psicologia da Saúde. ISPA. https://core.ac.uk/ download/pdf/154173853.pdf

Merhy, E. E. (1999). O ato de governar as tensões constitutivas do agir em saúde como desafio permanente de algumas estratégias gerenciais. Ciência \& Saúde Coletiva, 4(2), 305-314. https://dx.doi.org/10.1590/S1413$\underline{81231999000200006}$

Ministério da Saúde. (2014a). Cadernos de atenção básica: Núcleo de apoio a saúde da família, Volume I: ferramentas para gestão e para o trabalho cotidiano. Organização PanAmericana de Saúde. http://bvsms.saude.gov.br/bvs/ publicacoes/nucleo_apoio_saude_familia_cab39.pdf

Ministério da Saúde. (2014b). Atenção domiciliar no SUS: Resultados do laboratório de inovação em atenção domiciliar. Organização Pan-Americana da Saúde. http://bvsms. saude.gov.br/bvs/publicacoes/atencao_domiciliar_sus_ resultados_laboratorio_inovacao.pdf

Palmeira, A., \& Guerra, M. (2020). Atuação ética e contextualizada nos estágios básicos supervisionados em Psicologia da Saúde: um relato de experiência de docentes. Revista Psicologia, Diversidade e Saúde, 9(4), 482-494. http://dx.doi. org/10.17267/2317-3394rpds.v9i4.3025

Pietroluongo, A. P. C., \& Resende, T. I. M. (2007). Visita domiciliar em saúde mental: o papel do psicólogo em questão. Psicologia: Ciência e Profissão, 27(1),22-31. https://doi. org/10.1590/S1414-98932007000100003
Portaria $n^{\circ}$ 825, de 25 de abril de 2016. (2016). Redefine a Atenção Domiciliar no âmbito do Sistema Único de Saúde (SUS) e atualiza as equipes habilitadas. Diário Oficial da União. Ministério da Saúde. https://www.in.gov.br/materia/-/ asset_publisher/Kujrw0TZC2Mb/content/id/22685962/ do1-2016-04-26-portaria-n-825-de-25-de-abrilde-2016-22685827

Portaria $n^{\circ}$ 2.436, de 21 de setembro de 2017. (2017). Aprova a Política Nacional de Atenção Básica, estabelecendo a revisão de diretrizes para a organização da Atenção Básica, no âmbito do Sistema Único de Saúde (SUS). Diário Oficial da União. Ministério da Saúde. https:// bvsms.saude.gov.br/bvs/saudelegis/gm/2017/ prt2436_22_09_2017.html

Rocha, K. B., Conz, J., Barcinski, M., Paiva, D., \& Pizzinato, A. (2017). A visita domiciliar no contexto da saúde: uma revisão de literatura. Psicologia, Saúde \& Doenças, 18(1), 170-185. https://dx.doi.org/10.15309/17psd180115

Santos, E. M., \& Kirschbaum, D. I. R. (2009). A trajetória histórica da visita domiciliária no Brasil: uma revisão bibliográfica. Revista Eletrônica de Enfermagem, 10(1). https://doi. org/10.5216/ree.v10i1.8014

Silva, J. G, Mendonça, S. R, Jesus, M. L., Lobo, M. F., Alves, C. G. B., Sousa, M. F. L., Costa, C. H. (2016). Contribuição do Programa de Educação pelo Trabalho para Saúde para formação universitária. Revista Ciência em Extensão, 12(1), 105-113. https://ojs.unesp.br/index.php/revista proex/ article/view/1088/0

Silva, M. V. O. (Org.). (2007). In-tensa ex-tensa: A clínica psicossocial das psicoses. LEV/FFCH/UFBA. http://picica. dominiotemporario.com/intesaextensa(3).pdf

Silva, M. V. O., Souza, C. G., Oliveira, M. S., Mendonça, P. P., \& Hardman, L. V. (2009). Tecnologias psicossociais em saúde mental: Atenção a crise na psicose. Anais do XV Encontro Nacional da ABRAPSO - Psicologia Social e Políticas de Existência: Fronteiras e Conflitos. ABRAPSO. http://abrapso. org.br/siteprincipal/images/Anais XVENABRAPSO/477.\%20 tecnologias\%20psicossociais\%20em $\% 20$ sa\%DAde $\% 20$ mental.pdf

Sousa, D., Oliveira, I. F., \& Costa, A. L. F. (2015). Entre o especialismo e o apoio: psicólogos no Núcleo de Apoio à Saúde da Família. Psicologia USP, 26(3), 474-483. https:// doi.org/10.1590/0103-656420140059

Spink, M. J., \& Frezza, R. (2013). Práticas discursivas e produção de sentido: a perspectiva da psicologia social. In M. J. Spink (Org), Práticas Discursivas e Produção de Sentido no Cotidiano: aproximações teóricas e metodológicas (pp. 01. 20). Centro Edelstein de Pesquisas Sociais. 